\title{
Design, Analysis and Manufacturing of Double Scissors Lift Elevated by One Hydraulic Cylinder
}

\author{
${ }^{1}$ Wubshet Yimer, ${ }^{2}$ Yanshuang Wang \\ ${ }^{12}$ Mechanical Manufacture and Automation \\ ${ }^{12}$ Tianjin University of Technology \& Education \\ ${ }^{12}$ Tianjin, China
}

\begin{abstract}
The following paper describes the design, analysis and manufacturing of a hydraulic scissor lift having two levels elevated by one hydraulic cylinder. Scissor lifting machine is hydraulically operated with makes lifting simple by eluding bending onward to lift manually because the table is regulating to be lifted at a preferred height. There are predominantly hundreds of workers for lift tables in industrial, warehousing and delivery services. The addition of this device (lift table) makes job quicker, harmless and easier. The overall objective of this paper is to design and manufacture a double scissors lift device elevated by one hydraulic cylinder that can be used in the automobile sector. The machine is tested by lifting different weights and it is successful and can lift up to the recommended weight of $270 \mathrm{~kg}$ efficiently without any problem. Drafting \& drawing of hydraulic system scissor lift is done using solid works.
\end{abstract}

Key words - Scissor lifting; lift table; hydraulic cylinder automobile sector, Solid works

\section{INTRODUCTION}

A scissor lift is a vertical lifting device that consists of a platform. The mechanism incorporated to achieve this function is the use of linked, folding supports in a crisscross pattern, known as a pantograph [1]. A scissor lift provide the most economic, dependable and versatile methods of lifting loads, it has a few moving parts, which may only require lubricated. This lift table raises the load smoothly to any desired height. This mechanism is incorporated with a hydraulic cylinder and the top of the scissors is attached a table platform. This device will make use of the power generated from a hydraulic cylinder to raise or lower a platform. The scissor lifts can be classified as follows: Hydraulic lifts, pneumatic lifts and mechanical lifts.

Hydraulic scissor lifts are very powerful tool for applying a ton of force on the platform plate of component which is equally distributed on scissor arms [2].

A properly designed and equipped scissor lift enhances the logistic infrastructure, improving facility's competitiveness. They are provide optimum solution for lifting awkward shaped objects to comfortable working heights with least worker fatigue and physical strain. It also reduces back and muscle injuries by avoiding inappropriate manual lifting techniques. Besides these it helps to save time. The beneficiaries are those who are working directly on lifting parts in automotive assembly and repair sector. This paper presents the design and manufacturing of a scissors lift elevated by one hydraulic cylinder for the automotive industry.

The drawing of hydraulic scissor lift was done using solid works, Figure 1 shows the 3D modeling of double hydraulic scissor lift.

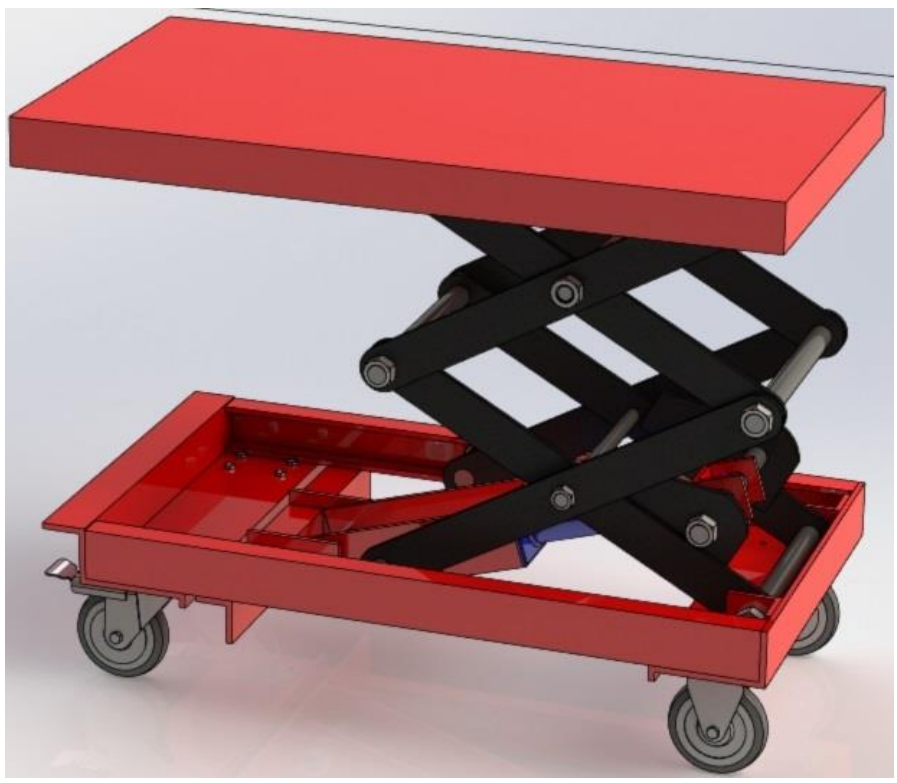

Fig.1. 3D modeling of hydraulic scissor lift

\section{Concept selection}

\section{DESIGN ANALYSIS}

The design was selected from an already made product in the market with modification in various parts and section to further enhance the functionality of the design.

\section{Design considerations}

Considerations made during the design and fabrication of a portable work platform being elevated by one hydraulic cylinder is as follows:

- Functionality of the design

- Manufacturability

- Economic availability, that is general cost of materials and fabrication techniques employed.

Research carried out in the automobile industry reveals that one of the heaviest components of the automobile car is the car engine which is of average weight of $272 \mathrm{~kg}$. By this factor, the control weight would be $280 \mathrm{~kg}$ for safer design of the scissor lift table platform for assembly purposes in the automotive industry. 


\section{Geometric Analysis}

Figure 2, shows geometry of the hydraulic scissor lifting machine in raised position, which shows the various dimensions of the links including their orientation at this position.

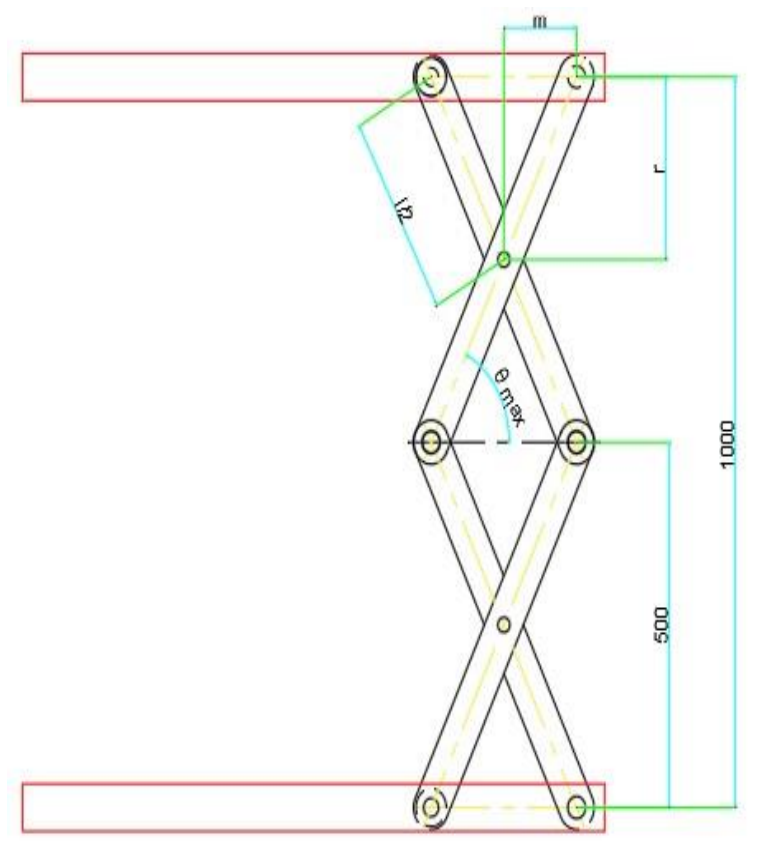

Fig.2. Geometry of the scissor lift in raised position

\section{Considering the upper position (Figure 2)}

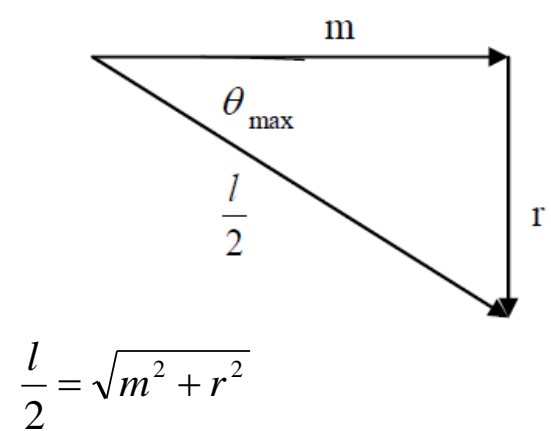

Where,

$1=$ the length of the arm

$\mathrm{m}=125 \mathrm{~mm}(1 / 2$ of the distance between the arm in raised position)

$r=250 \mathrm{~mm}(1 / 4$ of the height of the scissor in raised position)

Thus,

$$
\begin{aligned}
& l \\
& \frac{b}{2}=\sqrt{125^{2}+250^{2}} \\
& 12=280 \\
& =560 \mathrm{~mm} \text { (Scissor arm length) }
\end{aligned}
$$

The maximum arm/linkage angle ( $\theta_{\text {max }}$ )

The maximum angle between the links and an imaginary horizontal line occurs at the maximum lifting height.

Considering the lifted position (Figure2) $\theta_{\max }=$ opposite/ hypotenuse

$$
\begin{aligned}
\theta_{\text {max }} & =\sin ^{-1}\left(\frac{r}{l / 2}\right) \\
& =\sin ^{-1}\left(\frac{250}{560 / 2}\right) \\
& =\underline{63.23^{\circ}}
\end{aligned}
$$

Figure 3, shows geometry of the hydraulic scissor lifting machine in lowered position, which shows the various dimensions of the links including their orientation at this position.

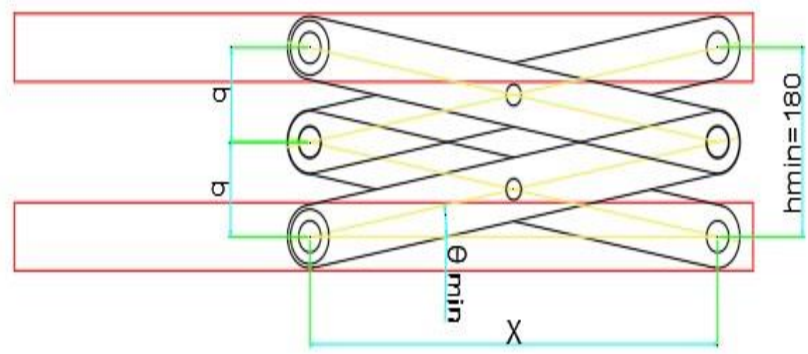

Fig.3. Geometry of the scissor lift in lowered position

\section{Considering the lowered position (Figure 3)}

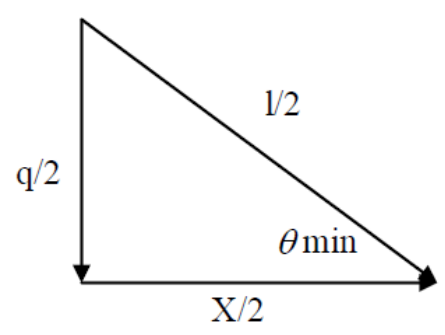

$$
\frac{X}{2}=\sqrt{\left(\frac{l}{2}\right)^{2}-\left(\frac{q}{2}\right)^{2}}
$$

Where,

$q=90 \mathrm{~mm}(1 / 4$ of the height of the scissor in lower position $)$

$\frac{X}{2}=\sqrt{\left(\frac{560}{2}\right)^{2}-\left(\frac{90}{2}\right)^{2}}$

$\frac{X}{2}=276 \mathrm{~mm}$

$\mathrm{X}=\underline{552 \mathrm{~mm}}$ (the distance between the link/ arm in lower position)

\section{The minimum arm/linkage angle $\left(\theta_{\text {min }}\right)$}

The minimum linkage angle between the links and an imaginary horizontal line occurs at the minimum (dead) height.

Considering the lowered position (Figure 3) 
$\theta_{\min }=$ opposite/ hypotenuse

$$
\begin{aligned}
\theta_{\min } & =\sin ^{-1}\left(\frac{q / 2}{l / 2}\right) \\
& =\sin ^{-1}\left(\frac{90 / 2}{560 / 2}\right)
\end{aligned}
$$

$\theta_{\min }=\underline{\underline{9.25^{0}}}$

\section{Actuator placement}

Figure 4, shows the actuator placement of scissor lift machine. The scissor lift uses the linear motion from a hydraulic actuator to produce large vertical displacement [3]. Several actuator constraints must be considered when selecting a location. These constraints include the minimum retracted length, maximum extended length, and maximum available force. Constraints imposed by the lift include strength of scissor members and space constraints imposed by the lift (and possibly by the payload). Proper actuator placement can significantly reduce the maximum force required of the actuator and also reduce the reaction forces at the lift joints [4].

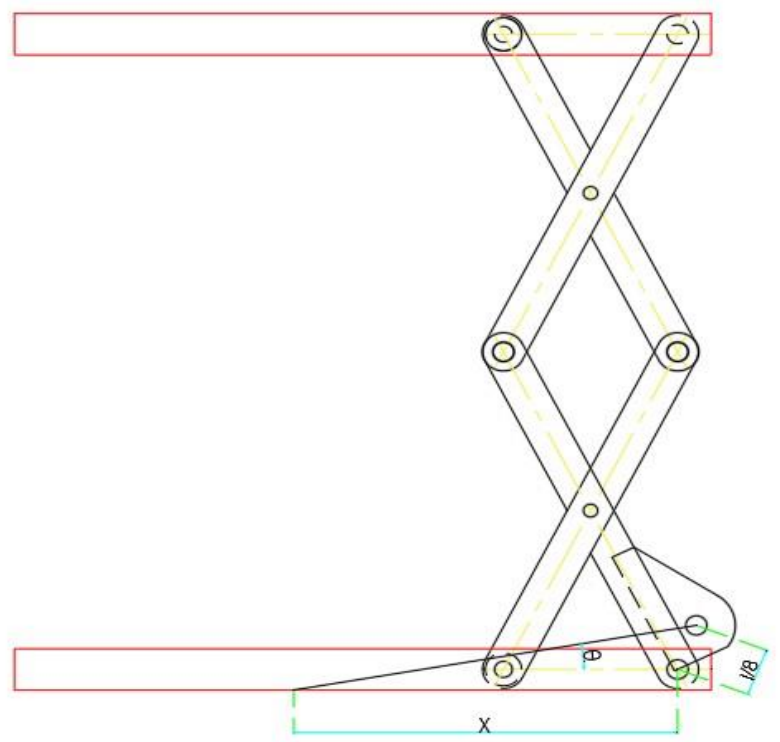

Fig.4. Actuator placement

$$
\begin{aligned}
& \theta=10^{0} \\
& \frac{l}{8}=\frac{560}{8}
\end{aligned}
$$

$=70 \mathrm{~mm}$

$\mathrm{X}=1 \cos 10^{0}$

$=560 \times \cos 10^{\circ}$

$\mathbf{X}=\underline{\underline{\mathbf{5 1 m}}}$ (actuator placement)

\section{Input parameters}

Table I - Input parameters

\begin{tabular}{|c|c|c|c|c|}
\hline S/N & Component & Symbol & Value & Unit \\
\hline 1 & Max allowable load & $\mathrm{W}$ & 280 & $\mathrm{~kg}$ \\
\hline 2 & Length of each scissor arm & 1 & 560 & $\mathrm{~mm}$ \\
\hline 3 & Max. lift of the platform & & 1000 & $\mathrm{~mm}$ \\
\hline 4 & Table platform dimensions & LXB & $1000 \times 520$ & $\mathrm{~mm}$ \\
\hline
\end{tabular}

\section{For Load type 1}

Reaction forces along the horizontal direction at the end of the first tier.

$\mathrm{EX}=-\mathrm{HX}=-\mathrm{GX}=\mathrm{F}=\frac{W}{2 \tan \theta}=\frac{2800}{2 \tan 63.23}$

$=\underline{\underline{707.07 \mathrm{~N}}}$

Horizontal force at the middle of the first tier $=\frac{W}{\tan \theta}=$ $\frac{2800}{\tan 63.23}=\underline{\underline{1414.14 N}}$

For load type 2, force couple EY= $\frac{F}{2}=\frac{W Y}{2}=\frac{2800}{2}$ $=\underline{\underline{1400 \mathrm{~N}}}$

$\mathrm{FY}=1400 \mathrm{~N}, \mathrm{~F}=\frac{M z}{l \cos \theta}, \quad \mathrm{EY}=\frac{F}{2}=\frac{M z}{l \cos \theta}$

$M z=2 l \cos \theta \times \mathrm{FY}=2 \mathrm{x} 0.56 \cos 63.23 \mathrm{X} 1414.14$

$$
=\underline{\underline{713.37 \mathrm{NM}}}
$$

$$
\begin{aligned}
\mathrm{CY} & =\mathrm{F}=2\left(\frac{M z}{l \cos \theta}\right) \text { or } \mathrm{Cy}=2\left(\frac{713.3}{0.56 \cos 63.23}\right) \\
& =\underline{\underline{2800 \mathrm{~N}}} \\
\mathrm{CX} & =0, \mathrm{EX}=0, \mathrm{FX}=0
\end{aligned}
$$

For loading type (3)

$\mathrm{F} \mathrm{X}=0, \mathrm{CX}=0, \mathrm{CY}=0$ and $\mathrm{CZ}=0$

$\mathrm{EY}=-\mathrm{DY}=\frac{M X}{2}$

Where $b=52 \mathrm{~cm}=0.52 \mathrm{~m}$, due to the symmetry of the system, $\mathrm{FY}=\mathrm{EY}$ and $\mathrm{GY}=\mathrm{DY}$

Therefore $M X=2 \mathrm{~b} X \mathrm{XY}=2 \mathrm{X} 0.52 \times 1400=\underline{\underline{1456 \mathrm{Nm}}}$

\section{Effort required raising the load}

To determine how much force you need, simply look at the angle of the pistons when the lift is collapsed. The force needed will be equal to the weight you want to raise times the sin of the piston angle [4].

$$
\begin{aligned}
\mathrm{F}_{\max } & =\mathrm{W}_{\mathrm{ma}} \times \sin \theta_{\min } \\
& =(280 \times 9.81) \times \sin 9.25 \\
& =2746 \times 0.61
\end{aligned}
$$


$=\underline{442 \mathrm{~N}} \ldots \ldots .$. Effort required raising the load

Table II - Results

\begin{tabular}{|c|c|c|c|c|c|}
\hline $\mathbf{S} / \mathbf{n}$ & $\begin{array}{c}\text { Load } \\
\text { type }\end{array}$ & Quantity & Symbols & Value & Unit \\
\hline 1 & & $\begin{array}{l}\text { Max. lift of scissor } \\
\text { arm }\end{array}$ & $\square \theta$ & 63.23 & $\begin{array}{c}\text { degr } \\
\text { ee }\end{array}$ \\
\hline \multirow{3}{*}{2} & \multirow{3}{*}{$\begin{array}{l}\text { Load } \\
\text { type } 1\end{array}$} & $\begin{array}{l}\text { Vertical force at the } \\
\text { end of first tier }\end{array}$ & $\begin{array}{c}\text { EY,FY,H } \\
\text { Y,GY }\end{array}$ & 700 & $\mathrm{~N}$ \\
\hline & & $\begin{array}{l}\text { Horizontal force at } \\
\text { the end of first tier }\end{array}$ & $\begin{array}{c}\text { EX,FX,H } \\
\text { X,GX }\end{array}$ & 707.07 & $\mathrm{~N}$ \\
\hline & & $\begin{array}{l}\text { Horizontal force at } \\
\text { middle of first tier }\end{array}$ & CX & 1414.14 & $\mathrm{~N}$ \\
\hline \multirow{3}{*}{3} & \multirow{3}{*}{$\begin{array}{l}\text { Load } \\
\text { type } 2\end{array}$} & $\begin{array}{l}\text { Vertical force at the } \\
\text { end of first tier }\end{array}$ & $\begin{array}{c}\text { EY,FY,H } \\
\text { Y,GY }\end{array}$ & 1400 & $\mathrm{~N}$ \\
\hline & & $\begin{array}{l}\text { Horizontal force at } \\
\text { the end of first tier }\end{array}$ & $\begin{array}{c}\text { EX,FX,H } \\
\text { X,GX }\end{array}$ & 0 & $\mathrm{~N}$ \\
\hline & & $\begin{array}{c}\text { Moment in the } \\
\text { z-direction in 1st tier }\end{array}$ & $\mathrm{MZ}$ & 713.37 & $\mathrm{Nm}$ \\
\hline \multirow{3}{*}{4} & \multirow{3}{*}{$\begin{array}{l}\text { Load } \\
\text { type } 3\end{array}$} & $\begin{array}{l}\text { Vertical force at the } \\
\text { end of first tier }\end{array}$ & $\begin{array}{c}\text { EY,FY,H } \\
\text { Y,GY }\end{array}$ & 1400 & $\mathrm{~N}$ \\
\hline & & $\begin{array}{l}\text { Horizontal force at } \\
\text { the end of first tier }\end{array}$ & $\begin{array}{c}\mathrm{EX}, \mathrm{FX}, \mathrm{H} \\
\mathrm{X}, \mathrm{GX} \\
\end{array}$ & 0 & $\mathrm{~N}$ \\
\hline & & $\begin{array}{c}\text { Moment in the } \\
\text { x-direction in 1st tier }\end{array}$ & MX & 1456 & $\mathrm{Nm}$ \\
\hline 5 & & $\begin{array}{l}\text { Effort required to } \\
\text { raise the load }\end{array}$ & & 442 & $\mathrm{~N}$ \\
\hline
\end{tabular}

\section{Strength and rigidity of the system}

The reaction force for load type $1 \& 2$ are all in the $\mathrm{x}-\mathrm{y}$, and are symmetric in the $x-y$ plane. Because of this a cross bracing is recommended between left and right side of the lift to increase rigidity of the system. Reaction force from load type $1 \& 2$ will completely unstressed cross bracing in the left and right side of the system. It may be used for buckling purpose. While load type 3 have a reaction force that may stress cross bracing. In most application the scissor lift operate on a level ground. In this application is the most important significant load, although load type 2 and 3 may also be present if the load at the top of the lift is not centered. The type of load determines the type and the amount of cross-bracing required. Load type $1 \& 2$ do not stress cross bracing as is not too small but load type 3 affect cross bracing. [4]

\section{MACHINE TESTING AND RESULT}

The scissor lifting machine is tested by lifting three different weights $(102,153,204$ and $272 \mathrm{~kg})$ in different heights. The first weight it has lifted is $102 \mathrm{~kg}$ and it lifts the weight smoothly without any disturbance. Secondly, it is tested by lifting $153 \mathrm{~kg}$; this weight has also been lifted without any problem and thirdly it has tested lifting $204 \mathrm{~kg}$ this weight also been lifted without any problem and Finally, by lifting $272 \mathrm{~kg}$. Which are the recommended weight and the weight is lifted smoothly with a higher effort than the $102 \mathrm{~kg}$ and $153 \mathrm{~kg}$.
Generally, the machine can lift the recommended weight 272 $\mathrm{kg}$ easily because the hydraulic piston makes lifting a high load easier and it does not have a disturbing sound.
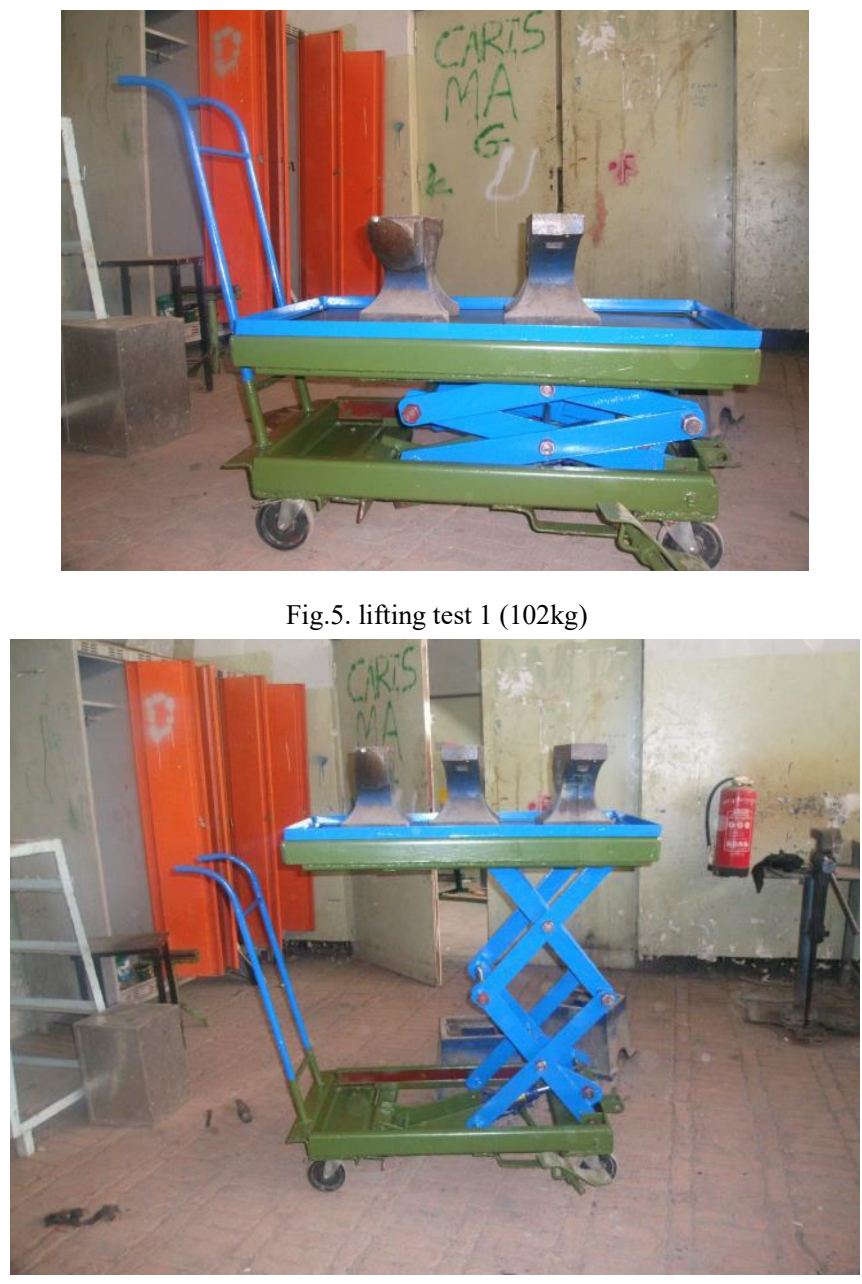

Fig.6. lifting test $2(153 \mathrm{~kg})$

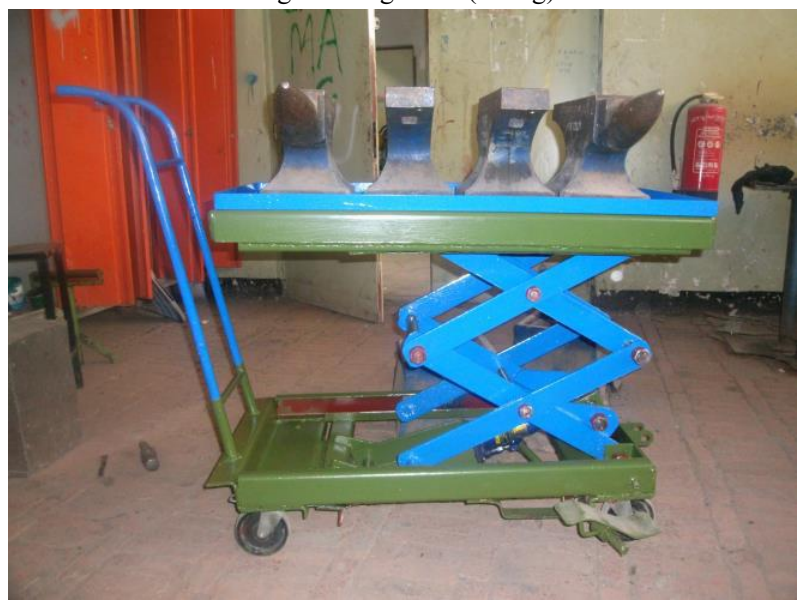

Fig.7. lifting test $3(204 \mathrm{~kg})$ 


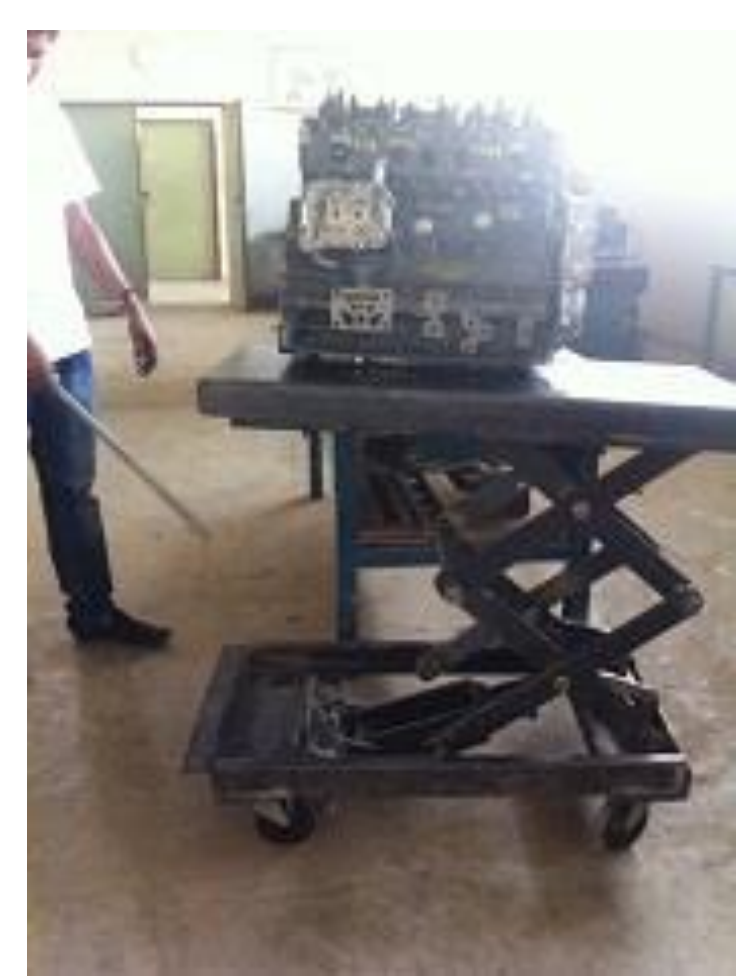

Fig.8. lifting engine test $4(270 \mathrm{~kg})$

\section{CONCLUSION}

The design and fabrication of a portable work platform elevated by one hydraulic cylinder was carried out effectively meeting the necessary design criteria. The double scissors lift elevated by one hydraulic cylinder is operated by the pedal. The scissor lift can be design for average load, because the higher the load the higher the effort required [2]. The hydraulic scissor lift is easy in use and does not required tedious repairs. It can also lift heavier loads. For the given dimensions the scissor lift can high a load up to $280 \mathrm{~kg}$ to the height of $1000 \mathrm{~mm}$. Hence, its extensive application in industries, hydraulic pressure system, for lifting of vehicle in garages, maintenance of huge machines, and for staking purpose.

\section{ACKNOWLEDGMENT}

I would like to appreciate the following: For my advisor Professor Yanshuang Wang for fruitful comments of the paper; Assistant professor Habtamu Beri for helpful comments at several stages of this study.

\section{REFERENCES}

[1] Thorat, S.G., A.R. Chiddarwar, and S.P. Prustyf, Design and Construction of Hydraulic Scissor Lift. 2017.

[2] Momin, G.G., et al., Design, manufacturing \& analysis of hydraulic scissor lift. International Journal of Engineering Research and General Science, 2015. 3(2 Part 2).

[3] Lee, S.-w., O. Kwon, and K.-H. Rim, Analysis and design of long-stroke linear actuators. Journal of Mechanical Science and Technology, 2014. 28(8): p. 3197-3202.

[4] Spackman, H., Mathematical Analysis of Scissor Lifts. 1989, NAVAL OCEAN SYSTEMS CENTER SAN DIEGO CA.

[5] Doli Rani, Nitin Agarwa land Vineet Tirth. Design and Fabrication of Hydraulic Scissor Lift. MIT International Journal of Mechanical Engineering, Vol. 5, No. 2, August 2015, pp. 81-87 ISSN 2230-7680 @ MIT Publications. 